\title{
Incidence of and Risk Factors for Skin Cancer in Organ Transplant Recipients in the United States
}

\begin{abstract}
Giorgia L. Garrett, MD; Paul D. Blanc, MD, MSPH; John Boscardin, PhD; Amanda Abramson Lloyd, MD; Rehana L. Ahmed, MD, PhD; Tiffany Anthony, MD; Kristin Bibee, MD, PhD; Andrew Breithaupt, MD; Jennifer Cannon; Amy Chen, MD; Joyce Y. Cheng; Zelma Chiesa-Fuxench, MD, MSCE; Oscar R Colegio, MD, PhD; Clara Curiel-Lewandrowski, MD; Christina A. Del Guzzo, MD; Max Disse; Margaret Dowd, MD; Robert Eilers Jr, MD; Arisa Elena Ortiz, MD; Caroline Morris, BA; Spring K. Golden, MD; Michael S. Graves, MD; John R. Griffin, MD; R. Samuel Hopkins, MD; Conway C. Huang, MD; Gordon Hyeonjin Bae, MD; Anokhi Jambusaria, MD; Thomas A. Jennings, MD, PhD; Shang I. Brian Jiang, MD; Pritesh S. Karia, MPH; Shilpi Khetarpal, MD; Changhyun Kim, MD; Goran Klintmalm, MD, PhD; Kathryn Konicke, BS; Shlomo A. Koyfman, MD; Charlene Lam, MD, MPH; Peter Lee, MD, PhD; Justin J. Leitenberger, MD; Tiffany Loh; Stefan Lowenstein; Reshmi Madankumar; Jacqueline F. Moreau, MD, MS; Rajiv I. Nijhawan, MD; Shari Ochoa, MD, MS; Edit B. Olasz, MD, PhD; Elaine Otchere, BS; Clark Otley, MD; Jeremy Oulton, MS; Parth H. Patel, BS; Vishal Anil Patel, MD; Arpan V. Prabhu, BS; Melissa Pugliano-Mauro, MD; Chrysalyne D. Schmults, MD, MSCE; Sarah Schram, MD; Allen F. Shih, AB, AM; Thuzar Shin, MD, PhD; Seaver Soon, MD; Teresa Soriano, MD; Divya Srivastava, MD; Jennifer A. Stein, MD, PhD; Kara Sternhell-Blackwell, MD; Stan Taylor, MD; Allison Vidimos, MD; Peggy Wu, MD; Nicholas Zajdel, BS; Daniel Zelac, MD; Sarah T. Arron, MD, PhD
\end{abstract}

IMPORTANCE Skin cancer is the most common malignancy occurring after organ transplantation. Although previous research has reported an increased risk of skin cancer in solid organ transplant recipients (OTRs), no study has estimated the posttransplant population-based incidence in the United States.

OBJECTIVE To determine the incidence and evaluate the risk factors for posttransplant skin cancer, including squamous cell carcinoma (SCC), melanoma (MM), and Merkel cell carcinoma (MCC) in a cohort of US OTRs receiving a primary organ transplant in 2003 or 2008.

DESIGN, SETTING, AND PARTICIPANTS This multicenter retrospective cohort study examined 10649 adult recipients of a primary transplant performed at 26 centers across the United States in the Transplant Skin Cancer Network during 1 of 2 calendar years (either 2003 or 2008) identified through the Organ Procurement and Transplantation Network (OPTN) database. Recipients of all organs except intestine were included, and the follow-up periods were 5 and 10 years.

MAIN OUTCOMES AND MEASURES Incident skin cancer was determined through detailed medical record review. Data on predictors were obtained from the OPTN database. The incidence rates for posttransplant skin cancer overall and for SCC, MM, and MCC were calculated per 100000 person-years. Potential risk factors for posttransplant skin cancer were tested using multivariate Cox regression analysis to yield adjusted hazard ratios (HR).

RESULTS Overall, 10649 organ transplant recipients (mean [SD] age, 51 [12] years; 3873 women [36\%] and 6776 men [64\%]) contributed 59923 years of follow-up. The incidence rates for posttransplant skin cancer was 1437 per 100000 person-years. Specific subtype rates for SCC, MM, and MCC were 812, 75, and 2 per 100000 person-years, respectively. Statistically significant risk factors for posttransplant skin cancer included pretransplant skin cancer (HR, 4.69; 95\% Cl, 3.26-6.73), male sex (HR, 1.56; 95\% Cl, 1.34-1.81), white race (HR, 9.04; $95 \% \mathrm{Cl}, 6.20-13.18)$, age at transplant 50 years or older ( $\mathrm{HR}, 2.77 ; 95 \% \mathrm{Cl}, 2.20-3.48)$, and being transplanted in 2008 vs 2003 (HR, 1.53; 95\% Cl, 1.22-1.94).

CONCLUSIONS AND RELEVANCE Posttransplant skin cancer is common, with elevated risk imparted by increased age, white race, male sex, and thoracic organ transplantation. A temporal cohort effect was present. Understanding the risk factors and trends in posttransplant skin cancer is fundamental to targeted screening and prevention in this population.

JAMA Dermatol. 2017;153(3):296-303. doi:10.1001/jamadermatol.2016.4920 Published online January 11, 2017. Corrected on February 1, 2017.
Supplemental content
Author Affiliations: Author affiliations are listed at the end of this article.

Corresponding Author: Sarah T. Arron, MD, PhD, Department of Dermatology, University of CaliforniaSan Francisco, 1701 Divisadero St, PO Box 0316, San Francisco, CA 94143-0316 (sarah.arron@ucsf.edu). 
$\mathrm{T}$ he number of solid organ transplants performed in the United States is increasing. In 1988, 12623 transplants were carried out nationwide; by 2015 this number has increased nearly 3-fold to 30 969. ${ }^{1}$ The lifelong immunosuppressive regimes required to preserve graft function place organ transplant recipients (OTRs) at increased risk of skin cancer, the most common tumor in this population. ${ }^{2-4}$ The risk of skin cancer is higher in OTRs than in the general population, 65 -fold for cutaneous squamous cell carcinoma (SCC) and 3-fold for malignant melanoma (MM). ${ }^{3-6}$ A number of risk factors for posttransplant skin cancer have been identified in single-center studies: being male, ${ }^{7,8}$ white, ${ }^{9-11} 50$ years or older at the time of transplant, ${ }^{6,7,12}$ a recipient of a thoracic organ, ${ }^{5,13}$ and having a longer time elapsed since transplant. ${ }^{13} \mathrm{~A}$ history of pretransplant treated skin cancer, ${ }^{14,15}$ as well as past overexposure to ultraviolet (UV) radiation ${ }^{16-18}$ are also believed to increase the risk of posttransplant skin cancer.

Multiple studies have highlighted the increasing problem of skin cancer in OTRs, though data are limited in key aspects. Although single-center studies have been published, incidence data across a wider transplant population are lacking. For example, Brewer et $\mathrm{al}^{7}$ found 0.43 skin cancers per patient per year (or 430 per 1000 patient-years) in a cohort of 312 heart transplant recipients seen at the Mayo Clinic, while Esfeh et al ${ }^{19}$ observed 84.8 skin cancer cases per 1000 person-years in a cohort of 998 liver transplant recipients at the Cleveland Clinic. Altogether, data for skin cancer among pancreas, ${ }^{20,21}$ liver, ${ }^{19,22}$ heart, ${ }^{7,23}$ and lung ${ }^{12}$ transplant recipients are limited, while incidence of skin cancer in kidney transplant has been a focus of studies. ${ }^{4,16,17,21,24-27}$ Thus, there is a need for reliable data estimating the incidence of skin cancer across all organ transplant types and subsuming a range of recognized risk cofactors. In this study, we combined national transplant registry data with skin cancer outcomes review to estimate a US population-based incidence of skin cancer and model risk associated with known or suspected risk factors for disease.

\section{Methods}

\section{Transplant Skin Cancer Network}

The Transplant Skin Cancer Network (TSCN) is led by the University of California, San Francisco, and includes 26 US transplant centers with an active collaboration between the dermatology and transplant services (eTable 1 in the Supplement). Participation in the TSCN was open to all transplant centers in the United States; 26 centers elected to participate in this network study based on access to registry and medical records and ethics approval for a multicenter study. The study was approved by the Committee on Human Research at the University of California, San Francisco, as well as at each participating center.

\section{Study Population}

Adult ( $\geq 18$ years) recipients of a primary transplant performed at participating transplant centers either between January 1 through December 31, 2003, or between January 1 through December 31, 2008, were eligible for inclusion. The 2 years studied were selected to enable a 5-year and 10-year fol-

\section{Key Points}

Question What is the population-based incidence of posttransplant skin cancer in the United States?

Findings In this population-based cohort study of 10649 organ transplant recipients, the incidence ratio for posttransplant skin cancer overall was 1437 per 100000 person-years. The specific subtype rates for squamous cell carcinoma, malignant melanoma, and Merkel cell carcinoma were 812, 75, and 2 per 100000 person-years, respectively.

Meaning Posttransplant skin cancer is common, with elevated risk imparted by specific risk factors.

low-up period to investigate differences in transplant cohorts between 2003 and 2008 and to capture changes in immunosuppressant regimes introduced between the 2 time periods, as well as other temporal trends. Transplanted organs included the lung, heart (either organ or heart-lung, referred to here as "thoracic" transplants), pancreas, liver, and kidney; intestinal transplants were excluded given the small number $(\mathrm{n}=36)$ and limited centers.

Eligible subjects were identified using the Standard Transplant Analysis and Research (STAR) file, based on Organ Procurement Transplant Network (OPTN) data as of December 2013. The OPTN database contains pretransplant and posttransplant data on every transplant event occurring in the United States since 1987; data are reported to the OPTN by transplant centers. Using the OPTN database, the demographics of our 26-center cohort were compared to those of all US recipients transplanted in either 2003 or 2008.

\section{Measurements}

\section{Outcome Variables}

The primary study outcome was time until diagnosis of any skin cancer and, separately, SCC, MM, or Merkel cell carcinoma (MCC) from the date of transplant. Outcome data were obtained from review of medical, transplant, dermatology, dermatopathology, and specialty records (otolaryngology, surgical oncology, radiation oncology, hematology-oncology). Written guidance on reviewing medical records and adjudicating outcomes was distributed by the lead center. Skin cancer was captured by the presence of a documented positive history. Skin cancer history was considered negative if it was documented as negative in the medical records or if a detailed medical history did not record any mention of skin cancer. Skin cancer history could not be determined and was marked as "missing" if there was no detailed general medical or dermatological history documented. Dates were entered in an electronic database (generated with REDCap software) in month-day-year format. If the day was not known, the first day of the month was entered. If only the year was known, January 1 of the year was entered.

\section{Predictor Variables}

Predictor variables drawn from the STAR file included sex, ${ }^{7,8}$ race, ${ }^{9-11}$ age at transplant, ${ }^{6,72}$ organ transplanted, ${ }^{5,13}$ year of transplant, ${ }^{13}$ and residential zip code at the time of transplantation. ${ }^{16-18}$ History of pretransplant skin cancer was 
established from record review. Predictors were selected based on previous research showing an effect on posttransplant skin cancer. MapQuest Open geocoding software (MapQuest Inc) was used to convert the zip code at the time of transplant into latitude coordinates, which were used as a proxy for pretransplant UV exposure..$^{28,29}$

\section{Statistical Analysis}

The incidence rate (IR) of skin cancer, SCC, MM, and MCC was calculated per 100000 person-years of observation. Patients were followed from the date of transplant until the earliest of skin cancer, death, or last follow-up. If the date of diagnosis was not known ( $n=120)$, the date of last follow-up, obtained from the medical record $(n=117)$ or from the STAR file $(n=3)$, was used. Cox regression analysis was used to test the associations between the independent predictor variables of interest on time until posttransplant skin cancer. Hazard ratios (HR) and 95\% CIs were adjusted for all predictors. Binary tests of interaction were performed, and the proportionality of hazards assumption was tested using the Schoenfeld test. To acknowledge clustering effects by transplant center, a shared frailty model with $\gamma$-distributed frailties was used in the Cox regression analysis (equivalent to a mixed model where the transplant center is a random effects variable). ${ }^{30}$ The skin cancer-specific HR was calculated in the presence of competing risk, defined as death from all causes, using the Fine and Gray proportional subhazard method. ${ }^{31}$ Competing risk regression yielded similar HRs as those obtained with Cox regression.

To investigate differences in transplant cohorts (transplant year 2003 vs 2008) and other temporal trends, all analyses were conducted for the overall cohort and stratified by transplant year 2003 vs 2008 (eTables 2-4 in the Supplement).

Several sensitivity analyses were conducted to account for missing data. Data missing more than $10 \%$ of observations were the outcomes of SCC (36\%), MM (36\%), MCC (37\%), and predictor of pretransplant skin cancer (39\%) (eTable 1 in the Supplement). On logistic regression analysis, thoracic OTRs and patients transplanted in southern latitudes were more likely to be missing outcomes. First, inverse probability weighting (ie, weighting on the inverse of the probability of not missing the outcome) was used to account for missing data. ${ }^{32} \mathrm{~A}$ logistic regression model for missing outcomes was developed, and the analysis was run adjusting for missing data through the weighting scheme. To acknowledge clustering effects by transplant center, the Huber/White method of cluster-robust standard error was applied to the Cox regression analysis. ${ }^{33}$ In a second sensitivity analysis, chained equations multiple imputation (MI) was performed. ${ }^{34}$ Twenty imputed data sets were created, and all missing outcomes and predictor were included. This strategy was limited by a significant overlap between the patients missing the outcomes and those missing the predictor. To address differential missingness of data between the participating centers, a third sensitivity analysis excluding centers with more than $20 \%$ of missing outcome data was performed. The final model was robust to the above sensitivity analyses; any differences in the results are noted in the results section.

\section{Results}

\section{Study Population}

A total of 10649 adult subjects received a primary transplant in 2003 ( $n=5004$ ) or 2008 ( $n=5645$ ), contributing 59923 personyears of follow-up. The median (interquartile range [IQR]) followup was 6 (3-8) years; 10 years in those transplanted in 2003 (IQR, $3-11$ ), and 6 years in those transplanted in 2008 (IQR, 3-7). At the end of follow-up, 6729 (63\%) patients were alive, 2773 (26\%) were deceased, and 1147 (11\%) were lost to follow-up.

Cohort demographics are summarized in Table 1, along with the national demographics of OTRs transplanted in 2003 or 2008. Compared to all OTRs who received a primary transplant in the United States in 2003 or 2008, our study group was older, had a higher proportion of white patients, and had undergone thoracic OTRs $(P<.001)$.

\section{Skin Cancer Incidence}

A total of 861 patients (8\%) developed posttransplant skin cancer, yielding an IR of 1437 per 100000 person-years (Table 2). The stratum-specific IR was highest for thoracic transplant recipients (2426 per 100000 person-years), whites (2039 per 100000 person-years), patients 50 years or older at transplant (2032 per 100000 person-years), men (1718 per 100000 person-years), and those transplanted in 2008 vs 2003 (1651 per 100000 person-years). Analysis of the renal transplant group specifically demonstrated that the stratum-specific IR for this subgroup was 1280 per 100000 person-years. The cumulative incidence of skin cancer-free survival was lower for those transplanted in 2008 vs 2003, as shown in the KaplanMeier plots in the Figure (log rank $P<.001)$ (eTable 2 in the Supplement presents the IR of skin cancer stratified by covariates for years of transplant 2003 and 2008). The majority ( $\mathrm{n}=812$ [94\%]) of skin cancers were SCC, yielding an IR of 1355 per 100000 person-years (Table 3). The incidence of posttransplant MM ( $\mathrm{n}=75$ ) was 125 per 100000 person-years. Only 2 cases of posttransplant MCC were documented.

\section{Predictors of Posttransplant Skin Cancer}

Several predictors of skin cancer were identified (Table 4). The adjusted HR for overall skin cancer was 4.69 (95\% CI, 3.616.09) in association with a history of previous pretransplant skin cancer $(P<.001), 1.61$ (95\% CI, 1.34-1.89) for male sex $(P<.001), 1.51$ (95\% CI, 1.26-1.82) for thoracic organ transplantation $(P<.001), 7.79$ (95\% CI, 5.34-11.37) for white race $(P<.001), 2.65$ (95\% CI, 2.12-3.21) for patients 50 years or older at transplant $(P<.001)$, and 1.59 (95\% CI, 1.33-1.91) for being transplanted in 2008 vs $2003(P<.001)$. Latitude was not statistically associated with skin cancer risk (HR, 1.01 [95\% CI, 0.99-1.02] per degree latitude; $P=.97$ ).

The adjusted HR for SCC and MM were similar to those for overall skin cancer (Table 4), falling short of statistical significance in MM due to the small number of events. A positive history of pretransplant MM had a higher HR (7.15 [95\% CI, 3.3115.46]; $P<$.001) compared with that observed for SCC or overall skin cancer (HR, 4.71 [95\% CI, 3.60-6.16] and 4.69 [95\% CI, 3.616.09], respectively; $P<.001)$. 


\begin{tabular}{|c|c|c|c|}
\hline Characteristic & Study Cohort & All OTR & $P$ Value \\
\hline Total, No. & 10649 & 44469 & \\
\hline \multicolumn{4}{|c|}{ Age at transplant, y } \\
\hline Mean (SD) & $51(12)$ & $50(13)$ & $<.001$ \\
\hline Median (IQR) & $53(44-60)$ & $52(42-60)$ & \\
\hline $18-29$ & $706(6)$ & $3347(7)$ & \multirow{6}{*}{$<.001$} \\
\hline $30-39$ & $1175(11)$ & $5319(12)$ & \\
\hline $40-49$ & $2242(21)$ & $9523(21)$ & \\
\hline $50-59$ & $3504(33)$ & $14301(32)$ & \\
\hline $60-69$ & $2532(24)$ & $10061(23)$ & \\
\hline$\geq 70$ & $490(5)$ & $1918(4)$ & \\
\hline$\geq 50$ & $6526(61)$ & $26280(59)$ & \multirow{2}{*}{$<.001$} \\
\hline$<50$ & $4123(39)$ & $18189(41)$ & \\
\hline \multicolumn{4}{|l|}{ Sex } \\
\hline Male & $6776(64)$ & $28116(63)$ & \multirow{2}{*}{.07} \\
\hline Female & $3873(36)$ & $16353(37)$ & \\
\hline \multicolumn{4}{|l|}{ Race } \\
\hline White & $7184(67)$ & $27762(63)$ & \multirow{5}{*}{$<.001$} \\
\hline Black & $1503(14)$ & 8555 (19) & \\
\hline Hispanic & $1239(11)$ & $5512(12)$ & \\
\hline Asian & $561(5)$ & $1914(4)$ & \\
\hline Other ${ }^{a}$ & $163(2)$ & $725(2)$ & \\
\hline White & $7184(67)$ & $27762(62)$ & \multirow{2}{*}{$<.001$} \\
\hline Nonwhite & 3465 (33) & $16706(38)$ & \\
\hline \multicolumn{4}{|l|}{ Organ } \\
\hline Lung $^{\mathrm{b}}$ & $981(9)$ & $2415(5)$ & \multirow{5}{*}{$<.001$} \\
\hline Heart & $1017(10)$ & $3456(7)$ & \\
\hline Kidney & $5158(48)$ & $26679(61)$ & \\
\hline Pancreas $^{c}$ & $386(4)$ & $1905(5)$ & \\
\hline Liver & 3107 (29) & $10014(21)$ & \\
\hline Thoracic & 1998 (19) & $5871(13)$ & \multirow{2}{*}{$<.001$} \\
\hline Abdominal & 8651 (81) & $38598(86)$ & \\
\hline \multicolumn{4}{|l|}{ Year transplanted } \\
\hline 2003 & $5004(47)$ & $21512(47)$ & \multirow{2}{*}{.90} \\
\hline 2008 & $5645(53)$ & $24471(53)$ & \\
\hline \multicolumn{4}{|l|}{ Latitude, ${ }^{\circ} \mathrm{N}^{\mathrm{d}}$} \\
\hline Mean (SD) & $39(7)$ & NA & \\
\hline Median (IQR) & $40(34-43)$ & NA & \\
\hline
\end{tabular}

Abbreviations: IQR, interquartile range; ${ }^{\circ} \mathrm{N}$, degrees north; OTR, organ transplant recipients.

a Includes American Indian or Alaska Native ( $n=79)$, Native Hawaiian or other Pacific Islander ( $n=37)$, multiracial $(n=46)$, and unknown $(n=1)$.

${ }^{\mathrm{b}}$ Includes heart-lung ( $\left.\mathrm{n}=15\right)$.

c Includes kidney-pancreas ( $\mathrm{n}=296$ ).

${ }^{d}$ Latitude coordinates were only available for the study cohort. The United States is located on the geographic coordinates of $40^{\circ} \mathrm{N}$ latitude and $100^{\circ} \mathrm{W}$ longitude in North America.
The HR obtained with inverse probability weighting in the first sensitivity analysis differed only with thoracic organ, and this not significantly. The nonsignificance of this predictor was likely due to collinearity between thoracic organ and transplant center, and this motivated our choice to use shared frailty models in the main analysis. Truncating weights at the 90th, 95th, and 99th centiles yielded similar HRs to inverse probability weighting analysis with no weight truncation.

\section{Discussion}

Incidence and Predictors of Skin Cancer in OTRs

This study provides a national patient population estimate for posttransplant skin cancer incidence in the United States. The IR of overall skin cancer was high at 1437 per 100000 personyears. Most cancers were SCC, which had the highest IR at 1355 per 100000 person-years. By comparison, the US general adult population age-adjusted IR of SCC is 38 per $100000 .^{35}$ The IR of MM was 125 per 100000 , also elevated compared with the general population rate of 9 to 18 per $100000 .{ }^{35,36}$ We observed 2 cases of MCC, compared with an expectation of 0.079 (based on an expected IR of 0.13 per 100000 in the general population). ${ }^{8}$ This yields the ratio of observed to expected of 25.3 (95\% CI, 3.1\%91.3\%) Poisson observation to its expectation. ${ }^{37}$ To further put these numbers into context, the skin cancer incidence rate in OTRs is nearly 5 times the rate of all cancers combined in the overall US population (448.7 per 100000$)$. $^{38}$

Our results highlight several risk factors for posttransplant skin cancer. The HR of posttransplant skin cancer was elevated in whites, men, thoracic transplant recipients, and patients 50 years or older at transplant. The corresponding IR for these groups underscore the magnitude of these effects: in whites the IR (per 100 000) was 2039, a 22-fold higher rate than 


\begin{tabular}{|c|c|c|}
\hline Characteristic & Skin Cancer, No. & Incidence Rate $(95 \% \mathrm{Cl})$ \\
\hline Total & 861 & $1436.83(1343.99-1536.01)$ \\
\hline \multicolumn{3}{|l|}{ Sex } \\
\hline Male & 641 & $1717.95(1589.98-1856.23)$ \\
\hline Female & 220 & $972.93(852.50-1110.38)$ \\
\hline \multicolumn{3}{|l|}{ Race } \\
\hline White & 824 & $2038.66(1904.11-2182.72)$ \\
\hline Nonwhite & 37 & $189.75(137.48-261.90)$ \\
\hline \multicolumn{3}{|l|}{ Organ } \\
\hline Thoracic & 261 & $2425.87(2148.72-2738.77)$ \\
\hline Abdominal & 600 & $1220.81(1126.93-1322.51)$ \\
\hline \multicolumn{3}{|l|}{ Age, y } \\
\hline$\geq 50$ & 702 & $2031.68(1886.82-2187.67)$ \\
\hline$<50$ & 159 & $626.69(536.48-732.08)$ \\
\hline \multicolumn{3}{|c|}{ Year transplanted } \\
\hline 2003 & 431 & $1272.38(1157.76-1398.36)$ \\
\hline 2008 & 430 & $1650.65(1501.78-1814.28)$ \\
\hline
\end{tabular}

${ }^{a}$ Incidence rate is expressed per 100000 person-years.

in nonwhites; for men, patients 50 years or older at transplant, and thoracic OTR, the IRs were 1.7-fold to 3-fold higher than for women, patients younger than 50 years at transplant, or abdominal OTRs, respectively.

\section{Effect of Era of Transplantation on Skin Cancer}

Patients transplanted in 2008 vs 2003 had a higher IR of skin cancer (1651 vs 1272 per 100000 person-years) (Table 2) (eTable 2 in the Supplement). We postulated that this might be due to improved documentation of skin cancer history in the more recent era (2008), but the difference persisted when the follow-up time was limited to 2009 and beyond (eTable 3 in the Supplement). We also postulated that the difference might be due to improved overall survival in the more recent era due to newer immunosuppressive agents, but the increase reflects adjustment for death as a competing risk. We postulate that the difference may be due to more aggressive immediate posttransplant immunosuppression in the more recent era. The risk model stratified by transplant year was not different to that of the overall cohort, so this temporal trend is not working through any of the risk factors (eTable 4 in the Supplement).

\section{Effect of Pretransplant UV Exposure on Skin Cancer}

We used latitude of residence as proxy for prior UV exposure and hypothesized that subjects living in southern latitudes have a higher incidence of posttransplant skin cancer. ${ }^{28,29,39}$ The HRs for other factors remained unchanged when latitude was removed from the model, and HRs remained unchanged in a model restricting to the US mainland latitude coordinates. There are several possible explanations for the absence of an effect of latitude on skin cancer. Although latitude is used as proxy for prior UV exposure in the general population, ${ }^{40-42}$ it may not be a good measure of pretransplant UV exposure in OTRs. Also, latitude coordinates were obtained by geocoding the patient's zip code at transplant, which may not represent the cumulative prior sun exposure ${ }^{43,44}$; survey data on previous sunburn may be a better

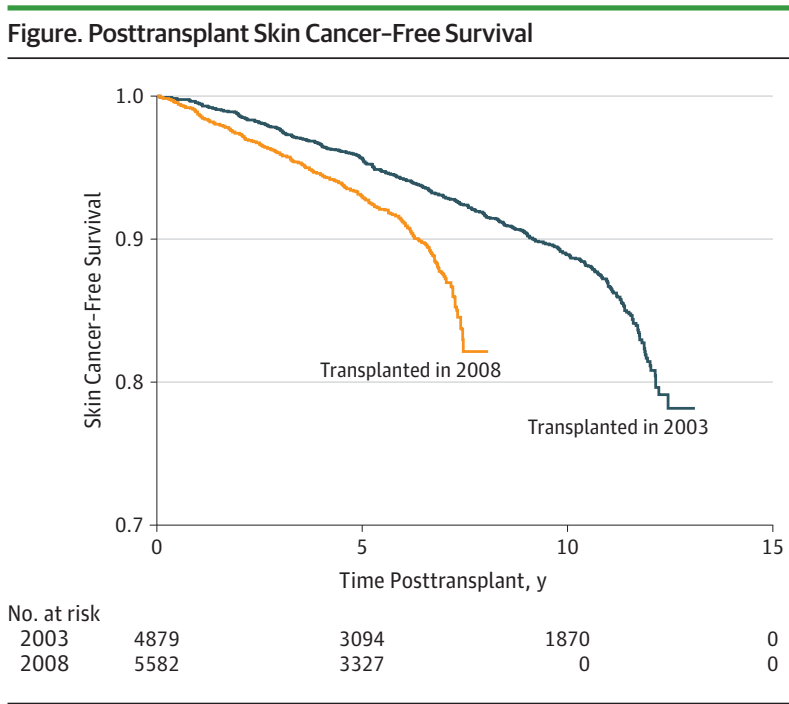

Kaplan-Meier plot showing the proportion of organ transplant recipients with skin cancer-free survival 1 to 15 years after their primary transplant, stratified by transplant year (2003 vs 2008). Overall, 10649 transplants are included; 5004 transplanted in 2003 and 5645 transplanted in $2008(P<.001$; log-rank test for difference in skin cancer-free survival between patients transplanted in 2003 vs 2008).

\begin{tabular}{lcc}
\hline \multicolumn{3}{l}{ Table 3. Posttransplant Incidence Rate (Overall, SCC, MM, and MCC) } \\
\hline Cancer Type & Total, No. & Incidence Rate $(95 \%$ Cl) \\
\hline All skin cancers & 861 & $1436.83(1343.99-1536.01)$ \\
\hline SCC & 812 & $1355.05(1264.98-1451.54)$ \\
\hline MM & 75 & $125.15(99.81-156.94)$ \\
\hline MCC & 2 & $3.33(0.83-13.34)$ \\
\hline
\end{tabular}

Abbreviations: MCC, Merkel cell carcinoma; MM, malignant melanoma;

SCC, squamous cell carcinoma.

${ }^{\mathrm{a}}$ Incidence rate is expressed per 100000 person-years.

proxy for prior UV exposure. Lastly, although UV radiation is an established skin carcinogen in the general population, ${ }^{44-46}$ the causality may not hold true in OTRs. Research using latitude, AVerage daily total GLObal solar radiation (AVGLO) exposure, and patient-based reports of prior sun exposure history points to a role for UV radiation in skin cancer incidence, but more reliable biomarkers of UV radiation may be needed to substantiate this hypothesis.

\section{Predictors of SCC and MM}

The magnitude and significance of the predictors in the model for overall skin cancer was driven by SCC. The model for MM had similar point estimates for the predictors, with wider CIs reflecting a smaller number of observed cases. The effect of pretransplant MM on posttransplant MM risk was larger than that observed for SCC (HR, 7.15; $P<.001$ vs HR, $4.71 ; P<.001)$. Arron et $\mathrm{al}^{47}$ observed a similar effect size in a cohort of 185039 OTRs in the United States where the HR for incident MM in patients with pretransplant MM was $5.4(P<.001) .{ }^{47}$

\section{Limitations}

The main limitation of this study was the imperfect capture of outcome data. The primary reason for missing skin cancer data 


\begin{tabular}{|c|c|c|c|c|c|c|}
\hline \multirow[b]{2}{*}{ Predictor } & \multicolumn{5}{|c|}{ Hazard Ratio $(95 \% \mathrm{CI})^{\mathrm{a}}$} & \multirow[b]{2}{*}{$P$ Value } \\
\hline & Skin Cancer & $P$ Value & SCC & $P$ Value & $\mathrm{MM}$ & \\
\hline \multicolumn{7}{|l|}{ Pretransplant skin cancer } \\
\hline No & 1 [Reference] & & 1 [Reference] & & 1 [Reference] & \\
\hline Yes & $4.69(3.61-6.09)$ & $<.001$ & $4.71(3.60-6.16)^{\mathrm{b}}$ & $<.001$ & $7.15(3.31-15.46)^{c}$ & $<.001$ \\
\hline Female & 1 [Reference] & & 1 [Reference] & & 1 [Reference] & \\
\hline Male & $1.61(1.34-1.89)$ & $<.001$ & $1.67(1.41-2.01)$ & $<.001$ & $1.26(0.73-2.20)$ & .41 \\
\hline \multicolumn{7}{|l|}{ Organ transplant } \\
\hline Abdominal & 1 [Reference] & & 1 [Reference] & & 1 [Reference] & \\
\hline Thoracic & $1.51(1.26-1.82)$ & $<.001$ & $1.53(1.265-1.85)$ & $<.001$ & $1.33(0.72-2.47)$ & .35 \\
\hline \multicolumn{7}{|l|}{ Race } \\
\hline Nonwhite & 1 [Reference] & & 1 [Reference] & & 1 [Reference] & \\
\hline White & $7.79(5.34-11.37)$ & $<.001$ & $8.18(5.49-12.18)$ & $<.001$ & $7.21(2.33-23.31)$ & .01 \\
\hline \multicolumn{7}{|l|}{ Age, y } \\
\hline$<50$ & 1 [Reference] & & 1 [Reference] & & 1 [Reference] & \\
\hline$\geq 50$ & $2.65(2.12-3.21)$ & $<.001$ & $2.73(2.24-3.34)$ & $<.001$ & $1.95(1.05-3.61)$ & .03 \\
\hline \multicolumn{7}{|l|}{ Year transplanted } \\
\hline 2003 & 1 [Reference] & & 1 [Reference] & & 1 [Reference] & \\
\hline 2008 & $1.59(1.33-1.91)$ & $<.001$ & $1.61(1.34-1.93)$ & $<.001$ & $1.65(0.89-3.06)$ & .11 \\
\hline Latitude & 1 [Reference] & & 1 [Reference] & & 1 [Reference] & \\
\hline Latitude, $1^{\circ} \mathrm{N}$ increase & $1.01(0.99-1.02)$ & .97 & $1.01(0.99-1.02)$ & .94 & $0.98(0.96-1.01)$ & .54 \\
\hline \multicolumn{3}{|c|}{ Abbreviations: MM, malignant melanoma; SCC, squamous cell carcinoma. } & \multicolumn{3}{|c|}{${ }^{\mathrm{b}}$ History of pretransplant SCC. } & \\
\hline \multicolumn{3}{|c|}{ a Hazard ratios are adjusted for other covariates. } & \multicolumn{2}{|c|}{ c History of pretransplant MM. } & & \\
\hline
\end{tabular}

was the failure to have a dermatologic history noted in the medical record. This may occur if patients were followed by dermatologists in the community and did not report their skin cancers to the transplant team. This limitation was addressed by comparing the results of several sensitivity analyses using methods to address missing data as previously noted. To account for variance between the 26 participating transplant centers, we incorporated a shared frailty model into the Cox regression to account for random effects due to transplant center.

As medical record documentation is the gold standard for skin cancer malignancy reporting, this study highlights the need for better documentation of skin cancer history. Posttransplant skin cancer can be reported to OPTN via malignancy reporting forms, but dermatologists may not be aware that the transplant team is able to register these tumors with OPTN. Future analysis of this data set will investigate the validity of OPTN posttransplant malignancy reporting for skin cancer.

Further, the sample was biased toward patients seen in academic transplant centers with a dermatology department. When comparing the TSCN cohort with all US patients transplanted in 2003 and 2008, there was a small but statistically significant increase in the proportion of subjects who were older, white, and a recipient of a thoracic transplant. Because these are known risk factors for posttransplant skin cancer, it is possible that our IR estimate is in the upper bounds of the true population value. Balanced against the potential for under-capture of skin cancer outcomes, we anticipate that these data achieve reasonable accuracy.

Prior research has demonstrated that specific immunosuppressive agents such as azathioprine confer increased risk for skin cancer in OTRs. Data on the duration and dosage of medication exposure required to inform this type of pharmacologic study was not available to this cohort since it is not included in the OTPN database. The utility of the data presented is to inform risk prediction at the time of transplant, before posttransplant drug exposures. Future research is needed to determine whether skin cancer risk can be mitigated through optimization of immunosuppressive regimes.

\section{Conclusions}

The high incidence of posttransplant skin cancer highlights the need for tumor surveillance after organ transplantation, especially in patients with high-risk features. These data can be used to inform risk stratification and screening guidelines for skin cancer in OTRs. To our knowledge, Germany executed the first nationwide skin cancer screening program for the general population in 2008; its effectiveness in reducing the mortality and morbidity of skin cancer is under evaluation. ${ }^{45,46,48}$ A follow-up goal of this study is to develop a prediction tool for posttransplant skin cancer.

\section{ARTICLE INFORMATION}

Correction: This article was corrected on February

1, 2017, for an incorrect author affiliation and an error in the abstract Results paragraph and the Findings paragraph of the Key Points.

Accepted for Publication: October 20, 2016.
Published Online: January 11, 2017. doi:10.1001/jamadermatol.2016.4920

Author Affiliations: University of California-San Francisco Medical Center, San Francisco (Garrett, 
Blanc, Boscardin, Lowenstein, Arron); Scripps Green Hospital, La Jolla, California (Lloyd, Graves, Otchere, Soon, Zelac); University of Minnesota Medical Center, Minneapolis (Ahmed, Disse, Lee, Schram); Baylor All Saints and Baylor University Medical Center, Dallas, Texas (Anthony, Griffin, Bae, Klintmalm); University of Pittsburgh, Pittsburgh, Pennsylvania (Bibee, P. H. Patel, Prabhu, Pugliano-Mauro); University of

California-Los Angeles Medical Center, Los Angeles (Breithaupt, Soriano); Mayo Clinic Florida, Jacksonville (Cannon, Jambusaria); Beth Israel Deaconess Medical Center, Boston, Massachusetts (Chen, Wu); Yale New Haven Hospital, New Haven, Connecticut (Cheng, Colegio, Shih); University of Pennsylvania, Philadelphia (Chiesa-Fuxench, Shin); University of Arizona Medical Center, Tucson (Curiel-Lewandrowski, Oulton); New York Presbyterian/Columbia University Medical Center, New York (Del Guzzo, Dowd, V. A. Patel); University of California-San Diego Medical Center, San Diego (Eilers, Ortiz, Jiang, Loh); Barnes-Jewish Hospital, St Louis, Missouri (Morris, Sternhell-Blackwell); Oregon Health and Science University, Portland (Golden, Hopkins, Leitenberger, Srivastava); University of Alabama Hospital, Birmingham (Huang, Jennings); Brigham and Women's Hospital, Boston, Massachusetts (Karia, Moreau, Schmults); Cleveland Clinic Foundation, Cleveland, Ohio (Khetarpal, Koyfman, Lam, Vidimos); Mayo Clinic Rochester, Rochester, Minnesota (Kim, Otley); Medical College of Wisconsin, Milwaukee (Konicke, Olasz, Zajdel); New York University Langone Medical Center, New York (Madankumar, Stein); University of Texas Southwestern Medical Center Parkland Memorial Hospital, Dallas (Nijhawan, Taylor); Mayo Clinic Arizona, Phoenix (Ochoa). Author Contributions: Drs Arron and Garrett had full access to all of the data in the study and take responsibility for the integrity of the data and the accuracy of the data analysis.

Concept and design: Garrett, Anthony, Cannon, Colegio, Ortiz, Jambusaria, Koyfman, Otley, Patel, Schmults, Wu, Arron.

Acquisition, analysis, or interpretation of data: Garrett, Blanc, Boscardin, Abramson Lloyd, Ahmed, Bibee, Breithaupt, Cannon, Chen, Cheng, Chiesa Fuxench, Colegio, Curiel-Lewandroski, Del Guzzo, Disse, Dowd, Eilers, Ortiz, Morris, Golden, Graves, Griffin, Hopkins, Huang, Bae, Jennings, Jiang, Karia, Khetarpal, Kim, Klintmalm, Konicke, Lam, Lee, Leitenberger, Loh, Lowenstein, Madakumar, Moreau, Nijhawan, Ochoa, Olasz, Otchere, Oulton, Patel, Prabhu, Pugliano-Mauro, Schmults, Schram, Shih Shin, Soon, Soriano, Srivastava, Stein, SternhellBlackwell, Taylor, Vidimos, Wu, Zajdel, Zelac, Arron. Drafting of the manuscript: Garrett, Blanc, Abramson Lloyd, Cannon, Dowd, Graves, Bae, Khetarpal, Oulton, Arron.

Critical revision of the manuscript for important intellectual content: Garrett, Blanc, Boscardin, Ahmed, Anthony, Bibee, Breithaupt, Chen, Cheng, Chiesa Fuxench, Colegio, Curiel-Lewandroski, Del Guzzo, Disse, Eilers, Ortiz, Morris, Golden, Griffin, Hopkins, Huang, Jambusaria, Jennings, Jiang, Karia, Kim, Klintmalm, Konicke, Koyfman, Lam, Lee, Leitenberger, Loh, Lowenstein, Madakumar, Moreau, Nijhawan, Ochoa, Olasz, Otchere, Otley, Oulton, P. Patel, V. Patel, Prabhu, Pugliano-Mauro, Schmults, Schram, Shih, Shin, Soon, Soriano, Srivastava, Stein, SternhellBlackwell, Taylor, Vidimos, Wu, Zajdel, Zelac, Arron. Statistical analysis: Garrett, Blanc, Boscardin,
Cannon, Cheng, Dowd, Eilers, Kim, Moreau, Shih, Srivastava, Arron.

Obtained funding: Arron, Kim.

Administrative, technical, or material support: Garrett, Abramson Lloyd, Bibee, Cannon, Cheng, CurielLewandroski, Del Guzzo, Disse, Ortiz, Golden, Huang, Jiang, Karia, Kim, Leitenberger, Nijhawan, Ochoa, Otley, Oulton, Shih, Shin, Soon, Zelac. Study supervision: Arron, Anthony, Cannon, Colegio, Disse, Garrett, Graves, Lee, Olasz, Ortiz, V. Patal, Schmults, Schram, Shih, Soriano, Stein. Conflict of Interest Disclosures: None reported. Funding/Support: This study was supported in part by the American Academy of Dermatology and Galderma; the Transplant Skin Cancer Network was funded by the American Academy of Dermatology and Galderma.

Role of the Funder/Sponsor: The funders/ sponsors had no role in the design and conduct of the study; collection, management, analysis, and interpretation of the data; preparation, review, or approval of the manuscript; and decision to submit the manuscript for publication.

\section{Additional Contributions: The authors} acknowledge Fatima Khan, BS; Srinath Senguttuvan, BS; J. Elliott Call, BS; Gabriela Soza, BS; Connie Tran, $\mathrm{BA}$; Bilal Fawaz, BS, for contributing to the collection of data for the study. All contributors are affiliated with the Baylor All Saints and Baylor University Medical Center and did not receive additional compensation for their contributions.

\section{REFERENCES}

1. United Network for Organ Sharing. Organ Procurement and Transplantation Network. http: //optn.transplant.hrsa.gov/latestData/rptData.asp. Accessed July 2, 2014.

2. Berg D, Otley CC. Skin cancer in organ transplant recipients: Epidemiology, pathogenesis, and management. J Am Acad Dermatol. 2002;47(1):1-17. 3. Zwald FO, Brown M. Skin cancer in solid organ transplant recipients: advances in therapy and management: part I. Epidemiology of skin cancer in solid organ transplant recipients. J Am Acad Dermatol 2011;65(2):253-261.

4. Kalinova L, Majek O, Stehlik D, Krejci K, Bachleda P. Skin cancer incidence in renal transplant recipients - a single center study. Biomed Pap Med Fac Univ Palacky Olomouc Czech Repub. 2010;154(3):257-260.

5. Zwald FO, Brown M. Skin cancer in solid organ transplant recipients: advances in therapy and management: part II. Management of skin cancer in solid organ transplant recipients. J Am Acad Dermatol. 2011;65(2):263-279.

6. Moloney FJ, Comber H, O'Lorcain P, O'Kelly P, Conlon PJ, Murphy GM. A population-based study of skin cancer incidence and prevalence in renal transplant recipients. Br J Dermatol. 2006;154(3):498-504.

7. Brewer JD, Colegio OR, Phillips PK, et al. Incidence of and risk factors for skin cancer after heart transplant. Arch Dermatol. 2009;145(12):1391-1396.

8. Vilar-Coromina N, Pérez Bueno F, Alsina Maqueda M, Vilardell Gil L, Izquierdo Font A, Marcos-Gragera R. Merkel cell cancer of the skin: population-based incidence and survival, 1995-2005 [in Spanish]. Med Clin (Barc). 2009;132(18):701-703.

9. Gogia R, Binstock M, Hirose R, Boscardin WJ, Chren MM, Arron ST. Fitzpatrick skin phototype is an independent predictor of squamous cell carcinoma risk after solid organ transplantation. J Am Acad Dermatol. 2013;68(4):585-591.
10. Bernat García J, Morales Suárez-Varela M, Vilata JJ, Marquina A, Pallardó L, Crespo J. Risk factors for non-melanoma skin cancer in kidney transplant patients in a Spanish population in the Mediterranean region. Acta Derm Venereol. 2013;93(4):422-427.

11. Tessari G, Girolomoni G. Nonmelanoma skin cancer in solid organ transplant recipients: update on epidemiology, risk factors, and management. Dermatol Surg. 2012;38(10):1622-1630.

12. Rashtak S, Dierkhising RA, Kremers WK, Peters SG, Cassivi SD, Otley CC. Incidence and risk factors for skin cancer following lung transplantation. J Am Acad Dermatol. 2015;72(1):92-98.

13. Krynitz B, Edgren G, Lindelöf B, et al. Risk of skin cancer and other malignancies in kidney, liver, heart and lung transplant recipients 1970 to 2008--a Swedish population-based study. Int J Cancer. 2013;132(6):1429-1438.

14. Traywick C, O'Reilly FM. Management of skin cancer in solid organ transplant recipients. Dermatol Ther. 2005;18(1):12-18.

15. Bouwes Bavinck JN, Hardie DR, Green A, et al. The risk of skin cancer in renal transplant recipients in Queensland, Australia. A follow-up study. Transplantation. 1996;61(5):715-721.

16. Fuente MJ, Sabat M, Roca J, Lauzurica R, Fernández-Figueras MT, Ferrándiz C. A prospective study of the incidence of skin cancer and its risk factors in a Spanish Mediterranean population of kidney transplant recipients. Br J Dermatol. 2003; 149(6):1221-1226

17. Borges-Costa J, Vasconcelos JP, Travassos AR, et al. Skin cancer in kidney transplant recipients: incidence and association with clinical and demographic factors [in Portuguese]. Acta Med Port. 2013;26(2):123-126

18. Terhorst D, Drecoll U, Stockfleth E, Ulrich C. Organ transplant recipients and skin cancer: assessment of risk factors with focus on sun exposure. Br J Dermatol. 2009;161(suppl 3):85-89. 19. Modaresi Esfeh J, Hanouneh IA, Dalal D, et al. The incidence and risk factors of de novo skin cancer in the liver transplant recipients. Int J Organ Transplant Med. 2012;3(4):157-163.

20. Spanogle JP, Kudva YC, Dierkhising RA, et al. Skin cancer after pancreas transplantation. J Am Acad Dermatol. 2012:67(4):563-569.

21. Loeffelbein DJ, Szilinski K, Hölzle F. Immunosuppressive regimen influences incidence of skin cancer in renal and pancreatic transplant recipients. Transplantation. 2009;88(12):1398-1399.

22. Herrero Jl, España A, D'Avola D, et al. Subsequent nonmelanoma skin cancer after liver transplantation. Transplant Proc. 2012-70;44(6):1568-1570.

23. Adamson R, Obispo E, Dychter S, et al. High incidence and clinical course of aggressive skin cancer in heart transplant patients: a single-center study. Transplant Proc. 1998;30(4):1124-1126.

24. Kasiske BL, Snyder JJ, Gilbertson DT, Wang C. Cancer after kidney transplantation in the United States. Am J Transplant. 2004;4(6):905-913.

25. Bannon FJ, McCaughan JA, Traynor C, et al Surveillance of nonmelanoma skin cancer incidence rates in kidney transplant recipients in Ireland. Transplantation. 2014;98(6):646-652.

26. Ramsay HM, Reece SM, Fryer AA, Smith AG Harden PN. Seven-year prospective study of nonmelanoma skin cancer incidence in U.K. renal transplant recipients. Transplantation. 2007;84(3): 437-439. 
27. Harden PN, Fryer AA, Reece S, Smith AG, Ramsay HM. Annual incidence and predicted risk of nonmelanoma skin cancer in renal transplant recipients. Transplant Proc. 2001;33(1-2):1302-1304. 28. Rivas M, Araya MC, Caba F, Rojas E, Calaf GM. Ultraviolet light exposure influences skin cancer in association with latitude. Oncol Rep. 2011;25(4): 1153-1159.

29. Hu S, Ma F, Collado-Mesa F, Kirsner RS. UV radiation, latitude, and melanoma in US Hispanics and blacks. Arch Dermatol. 2004;140(7):819-824. 30. Sahu SK, Dey DK, Aslanidou H, Sinha D. A Weibull regression model with gamma frailties for multivariate survival data. Lifetime Data Anal. 1997; 3(2):123-137.

31. Fine J, Gray R. A proportional hazards model for the subdistribution of a competing risk. J Am Stat Assoc. 1999;94(446):496-509.

32. Seaman SR, White IR. Review of inverse probability weighting for dealing with missing data. Stat Methods Med Res. 2013;22(3):278-295.

33. Huber PJ. The behavior of maximum likelihood estimates under nonstandard conditions. Proceedings of the Fifth Berkeley Symposium on Mathematical Statistics and Probability; 1967:221-233.

34. Sterne JA, White IR, Carlin JB, et al. Multiple imputation for missing data in epidemiological and clinical research: potential and pitfalls. BMJ. 2009;338:b2393.
35. Tejera-Vaquerizo A, Descalzo-Gallego MA, Otero-Rivas MM, et al. Skin Cancer Incidence and Mortality in Spain: A Systematic Review and Meta-Analysis. Actas Dermosifiliogr. 2016;107(4) 318-328.

36. Katalinic A, Eisemann N, Waldmann A. Skin cancer screening in Germany: documenting melanoma incidence and mortality from 2008 to 2013. Dtsch Ärzteblatt Int. 2015;112(38):629-634

37. Bailar J, Ederer F. Significance factors for the ratio of a Poisson variable to its expectation. Biometrics. 1964;20(3):639-643.

38. National Cancer Institute. Surveillance, Epidemiology, and End Results Program. http://seer .cancer.gov/statfacts/. Accessed June 20, 2007.

39. Eide MJ, Weinstock MA. Association of UV index, latitude, and melanoma incidence in nonwhite populations--US Surveillance, Epidemiology, and End Results (SEER) Program, 1992 to 2001. Arch Dermatol. 2005;141(4):477-481.

40. Godar DE. UV doses worldwide. Photochem Photobiol. 2005;81(4):736-749.

41. Moan J, Grigalavicius $M$, Baturaite Z, Dahlback A, Juzeniene $A$. The relationship between UV exposure and incidence of skin cancer. Photodermatol Photoimmunol Photomed. 2015;31(1):26-35.

42. Juzeniene A, Grigalavicius $M$, Baturaite $Z$, Moan J. Minimal and maximal incidence rates of skin cancer in Caucasians estimated by use of sigmoidal UV dose-incidence curves. Int J Hyg Environ Health. 2014;217(8):839-844.

43. Harwood CA, Mesher D, McGregor JM, et al. A surveillance model for skin cancer in organ transplant recipients: a 22-year prospective study in an ethnically diverse population. Am J Transplant. 2013;13(1):119-129.

44. Urwin HR, Jones PW, Harden PN, et al. Predicting risk of nonmelanoma skin cancer and premalignant skin lesions in renal transplant recipients. Transplantation. 2009;87(11):1667-1671.

45. Waldmann A, Nolte $S$, Weinstock MA, et al. Skin cancer screening participation and impact on melanoma incidence in Germany--an observational study on incidence trends in regions with and without population-based screening. Br J Cancer. 2012;106(5):970-974.

46. Stang A, Jöckel KH. Does skin cancer screening save lives? A detailed analysis of mortality time trends in Schleswig-Holstein and Germany. Cancer. 2016;122(3):432-437.

47. Arron ST, Raymond AK, Yanik EL, et al. Melanoma Outcomes in Transplant Recipients With Pretransplant Melanoma. Dermatol Surg. 2016;42 (2):157-166.

48. Choudhury K, Volkmer B, Greinert R, Christophers E, Breitbart EW. Effectiveness of skin cancer screening programmes. Br J Dermatol. 2012; 167(suppl 2):94-98.

\section{NOTABLE NOTES}

\section{Early Reports of "Sycosis"}

Niki Papavramidou, PhD; Anthony Karpouzis, PhD

Sycosis is a medical term that creates confusion in the ancient texts. The term is used for both the description of a skin disease and for trachoma. This Notable Note aims at shedding light on the skin disease defined as sycosis, after the Greek term for "fig" (бúko)-since its appearance resembles the inner part of the fruit-and presenting the descriptions of ancient authors.

According to Galen (AD 2nd century ), Archigenes (AD 1st century) defined sycosis as exanthemata of the beard, also called mentagra

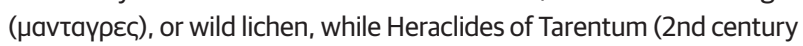
$\mathrm{BC}$ ) described sycosis of the head and beard as having the form of protruding ulcers. ${ }^{1}$ Galen himself described sycosis as small, hard ulcers appearing on the beard that are composed partly of thick and partly of thin serous humor and ulcerating rapidly if not treated with highly drying medicaments. ${ }^{1}$ Celsus (AD 1st century) described sycosis as an ulceration of 2 types, both appearing in areas covered by hair: (1) indurated and circular ulceration and (2) moist ulceration with an irregular outline. In the first type, which appears mostly on the beard, there is a scanty and glutinous discharge, while in the second type, which appears mainly on the scalp, the discharge is abundant and malodorous. ${ }^{2}$ Pliny the Elder (AD 1st century) wrote of an affliction called mentagra in Latin, or lichen in Greek, that affected mainly the upper-class citizens and was dispersed through kissing. Aetius of Amida (AD 5-6th century), Paulus Aegineta (AD 7th century), and Paulus Nicaaensis (circa AD 7th-10th centuries) described as sycosis either infections of the eyelids or "ulcerous excrescences which are round, somewhat hard, red, and accompanied with pain" arising mostly on the head but also on other parts of the body. ${ }^{3}$
From a modern point of view, sycosis is defined as an edematous growth in form of a fig, usually concerning folliculitis involving the cutaneous areas covered by beard hair. Anatomically, it is characterized by formation of pustular nodules or even intradermal abscesses. There are 2 different anatomoclinical forms of sycosis: staphylococcal sycosis and fungal sycosis. The "indurated and circular ulceration" described by Celsus may correlate with Tinea barbae, the most common responsible agent for fungal sycosis. As far as Celsus's description of sycosis as "moist, with irregular outline ulceration" is concerned, he may have been referring to Celsus kerion of the scalp hair or less possibly staphylococcal infection in Quinquaud folliculitis decalvans (neutrophilic cicatricial alopecia), found in patients with a deficient host immune response. Finally, the descriptions of Paulus Aegineta, Aetius, and Paulus Nicaaensis possibly referred to the whitish follicles of the inner eyelid appearing in trachoma, a contagious affection caused by Chlamydia trachomatis.

Author Affiliations: Department of History of Medicine, School of Medicine, Aristotle University of Thessaloniki, Thessaloniki, Greece (Papavramidou); Dermatology, Department of Dermatology, University Hospital of Alexandroupolis, Alexandroupolis, Greece (Karpouzis).

Corresponding Author: Niki Papavramidou, PhD, Department of History of Medicine, School of Medicine, Aristotle University of Thessaloniki, Thessaloniki, 54124, Greece (papavramidou@hotmail.com).

1. Kuhn CG, ed. Claudii Galeni Opera Omnia. Vol. 12; Leipzig, Germany: Knobloch; 1830:823-824, 846-848.

2. Spencer WG, ed. De Medicina. Cambridge, MA: Harvard University Press; 1971: 181.

3. Adams F, ed. The Seven Books of Paulus Aegineta. London, England: Syndenham Society of London; 1844:347. 